\title{
Epidemiology of Personal Watercraft Injuries
}

\section{Richdeep S. Gill1*\#, Kevin A. Whitlock ${ }^{2 \#}$, Abhinit S. Jawanda ${ }^{3}$, Sumeet S. Gill ${ }^{4}$ and Shahzeer Karmali ${ }^{5}$}

${ }^{1}$ Department of Surgery, University of Alberta, Edmonton, Alberta, Canada

${ }^{2}$ Faculty of Medicine \& Dentistry, University of Alberta, Edmonton, Alberta, Canada

${ }^{3}$ Department of Biological Sciences, University of Manitoba, Winnipeg, Manitoba, Canada

${ }^{4}$ Department of Kinesiology, University of Calgary, Alberta, Canada

${ }^{5}$ Center for the Advancement of Minimally Invasive Surgery (CAMIS), Royal Alexandria Hospital, Edmonton, Alberta, Canada

\#Equal contribution to the manuscript

\begin{abstract}
The popularity of extreme water sports has been steadily increasing over the last decade. Personal Watercraft (PWC) users are at the forefront of this rise. Individuals straddle a vehicle similar to a motorcycle and travel at high speeds, unrestrained across the water. Unfortunately this extreme activity is associated with significant risk of injury when accidents occur. Recent reports from the US coast guard suggest that PWC users are second only to open motorboats in terms of total marine accidents. Individuals commonly suffer orthopedic and closed head injuries due to the sudden deceleration secondary to a collision. Fractures are common and can be life threatening when the head and neck region is involved. Interestingly, PWC related deaths are less likely to occur from drowning and more likely secondary to blunt trauma. This phenomenon is in stark contrast to other open motorboat injuries. As well, rare perineal and lower abdominal injuries have been reported to occur when PWC passengers fall off the back of the vehicle. Without proper equipment the water jet causes significant trauma to the rectum and perineum. Many trauma experts have recommended changes to safety regulations that include better equipment, increased training for young and inexperienced users, improved protective behaviors while riding and improved PWC design. Without the industry, regulators and users making these changes it is unlikely that accidents and injuries from this extreme sport will decrease any time soon.
\end{abstract}

Keywords: Personal watercraft; Jet-ski; Trauma; Injury; Water sport

\section{Introduction}

Water sports continue to become increasingly popular and this has led to many people trying more extreme water activities. This includes the use of water sport vehicles, such as the Personal Watercrafts (PWC). PWC are single or dual passenger vehicles that travel at high speeds across the water. They are known commonly by their brand names as jet skis, seadoos and wave-runners. If boats are the cars of the water, then PWCs are certainly the motorcycles. With this extreme activity comes the risk of accident and injury (Table 1). The United States (US) coast guard is becoming increasingly aware of the rates and types of injuries sustained on PWCs. Orthopedic injuries, such as fractured bones, secondary to collisions are by far the most common. Our objective in this review is to explore common and rare PWC-related injuries. Rare injuries include perineal and lower abdominal injuries. In addition, we highlight the need for improved safety standards and education for PWC users.

\section{Epidemiology}

According to the US Coast Guard, PWC accounted for the second most marine accidents in 2010; the first being open motorboats [1]. A total of 814 incidents were reported to the coast guard with 776 non-fatal injuries and 38 deaths. The most common injuries sustained were fractures, lacerations, scrapes/bruises and concussions. Of the 38 deaths, only $24 \%$ were the result of drowning. In contrast a majority $(66 \%)$ of deaths involving open motorboats were secondary to drowning. Interestingly, the only vehicles to be involved with less drowning-related deaths are houseboats at $20 \%$. PWC are unique, in that the most common cause of death is related to blunt trauma at $58 \%$. These individuals were typically wearing life jackets during the PWC collision, which highlights the need for additional protective equipment. Life jackets may prevent drowning, but have limited ability to prevent injury during a collision; especially to the head and neck. Unfortunately, non-fatal orthopedic injuries are not only devastating, but also very common in PWC accidents.

\section{Common injuries}

PWC users are likely to suffer serious injuries when they are involved in a collision. These include fractures, lacerations, bruises and concussions. These aquatic vehicles travel at high speeds across the water and their passengers are rarely wearing protective equipment to mitigate impacts with the water, other crafts, or inanimate objects. During a sudden deceleration, the PWC driver may strike the handlebars or be ejected from the vehicle. Furthermore, PWC users may not be using the vehicle for safe leisure purposes; rather riders may be racing or making risky maneuvers, as it remains an exhilarating ride. Unfortunately, there is a paucity of literature reporting the serious outcomes of common PWC accidents. Vernberg et al. [2] published the first report of injuries related to PWC in 1989; more than a decade after these vehicles became available. They described an incident involving six PWC riders and six swimmers, of which ten were hospitalized and two died due to head trauma. Tsai et al. [3] reported a case of a 10-yearold girl who struck a boulder while driving a PWC at 30 miles per hour. The rapid deceleration led an open-book pelvic fracture, secondary to her pelvis striking the steering column while her head struck the handlebars. The authors highlighted in their case report, the dangers of allowing young, inexperienced individuals to operate such powerful

*Corresponding author: Richdeep S. Gill, 9-50 Medical Science Building University of Alberta, Edmonton, Alberta, T6G 2R3, Canada, Tel: 780-407-6325; Fax: 780-407-3283; E-mail: richdeep@ualberta.ca

Received January 23, 2012; Accepted February 06, 2012; Published February 10, 2012

Citation: Gill RS, Whitlock KA, Jawanda AS, Gill SS, Karmali S (2012) Epidemiology of Personal Watercraft Injuries. J Trauma Treatment 1:112 doi:10.4172/2167-1222.1000112

Copyright: (c) 2012 Gill RS, et al. This is an open-access article distributed under the terms of the Creative Commons Attribution License, which permits unrestricted use, distribution, and reproduction in any medium, provided the original author and source are credited. 


\begin{tabular}{|c|c|c|c|c|c|c|c|}
\hline Study & $\mathrm{N}$ & Male (\%) & Female (\%) & Mean Age & Injury Location & Mechanism of Injury & Deaths \\
\hline Jones et al. [7] & 248 & 64 & 36 & 22.4 & $\begin{array}{l}\text { Head/Neck } 14 \% \\
\text { Thorax/Abdomen } 4 \% \\
\text { Upper Extremity } 7 \% \\
\text { Lower Extremity } 20 \% \\
\text { Unspecified } 54 \%\end{array}$ & Collision with PWC 48\% & 5 \\
\hline Haan et al. [5] & 24 & 67 & 33 & 30 & $\begin{array}{l}\text { Head } 54 \% \\
\text { Face } 8 \% \\
\text { Spine } 29 \% \\
\text { Thorax } 21 \% \\
\text { Abdomen } 4 \% \\
\text { Pelvis } 4 \% \\
\text { GU* } 8 \% \\
\text { Extremity } 21 \% \\
\end{array}$ & $\begin{array}{l}\text { Collision } 46 \% \\
\text { Fall } 8 \% \\
\text { Axial Load } 21 \% \\
\text { Hydrostatic Jet } 4 \% \\
\text { Handlebar } 4 \% \\
\text { Combination } 17 \%\end{array}$ & 0 \\
\hline Kim et al. [4] & 62 & 66 & 34 & 23 & $\begin{array}{l}\text { Head } 35 \% \\
\text { Face } 27 \% \\
\text { Spine } 18 \% \\
\text { Thorax } 27 \% \\
\text { Abdomen } 13 \% \\
\text { Pelvis } 10 \% \\
\text { Upper Extremity } 6 \% \\
\text { Lower Extremity } 42 \%\end{array}$ & Collision PWC† 56\% & 1 \\
\hline Rubin et al. [6] & 66 & 60.6 & 39.4 & 12.3 & $\begin{array}{l}\text { Head/Face/Neck } 55.1 \% \\
\text { Spine } 1.2 \% \\
\text { Thorax } 9.5 \% \\
\text { Abdomen } 5.4 \% \\
\text { Pelvis } 3.3 \% \\
\text { Extremities } 17.3 \% \\
\text { Superficial } 8.2 \%\end{array}$ & $\begin{array}{l}\text { Collision PWC 33\% } \\
\text { Collision fixed object 21\% } \\
\text { Collision boat } 15 \% \\
\text { Fall } 9 \% \\
\text { Swimmer } 6 \% \\
\text { unknown } 7 \%\end{array}$ & 4 \\
\hline $\begin{array}{l}\text { Carmel et al. } \\
{[13]}\end{array}$ & 8 & 87.5 & 12.5 & 36 & Spine $100 \%$ & $\begin{array}{l}\text { Wave Jumping } 75 \% \\
\text { Fall } 25 \%\end{array}$ & 0 \\
\hline
\end{tabular}

${ }^{*} \mathrm{GU}=$ Gynecologic/Urologic injury

†Collision PWC = collision with another Personal Water Craft

‡Swimmer = struck by PWC while swimming

Table 1: Summary of Personal Watercraft (PWC) Injuries

vehicles. Following numerous case studies, trauma databases have been reviewed to better estimate PWC related injuries. Kim et al. [4] performed a retrospective review of the trauma registry for San Diego County, California from 1984 to 1997. They identified a total of 62 PWC related injuries, with the mean age of injured riders being 23 years. The major locations of injuries were the head, face, chest and thighs. The majority of the injuries to the head were lacerations; however serious injuries included skull fractures and closed head injuries. In addition, $39 \%$ of these individuals reported loss of consciousness. Alternatively, femur fractures were the most common extremity injury. A single death was reported secondary to a C2-3 fracture-dislocation and internal jugular vein disruption. Interestingly, $68 \%$ of the individuals were driving the PWC at the time of injury and $56 \%$ of the accidents were the result of a collision with another PWC. Haan et al. [5] performed a retrospective review of the Maryland trauma registry and identified 24 PWC related incidents over a five year period. Of these incidents, $46 \%$ were secondary to collisions with other PWCs or inanimate objects. In addition, 13 individuals had traumatic brain injuries and seven others had spinal injuries. A study by Rubin et al. [6] utilized a US national database on PWC related injury in the pediatric population over a 10 -year period and identified 66 patients. They found that $70 \%$ of the pediatric patients suffered collision injuries, with the head/neck region being involved in the majority of cases (55.1\%). As well, four patients died secondary to collision with an object (another boat or the dock). The authors cited trauma to the head as a significant contributor to death. Notably, none of these children were wearing helmets. Overall head injuries are estimated to account for $14-20 \%$ of PWC injuries, but as Rubin et al. [6] highlight, this can be as high as $55.1 \%$ in the pediatric population $[4,7]$. Head injuries include but are not limited to cerebral contusions, subdural and epidural hematomas and skull fractures and may result in quadriplegia or paraplegia. In 2011, Pikora et al. [8] published an interesting study, which recruited 145 recreational water enthusiasts to complete a survey pertaining to their extreme water sport. Of these participants, 47 individuals reported activity on PWC. 97.9\% of these individuals had a recreational skipper's ticket, which certifies that at least minimal practical skills and knowledge exist to operate a PWC. The authors analyzed the injury rate of these PWC users and found that $28 \%$ had an injury within the past year. This equated to an injury rate of 4.5 injuries/100 hours of exposure. Landing awkwardly on the water was the most common mechanism of injury. However, these results are limited by potential bias associated with selfreported answers. It is possible that individuals under-reported certain negative behaviors and over-reported the use of personal protective equipment. Nonetheless, these studies provide insights into possible injuries that occur, not requiring emergent medical attention and thus go unreported to trauma databases.

\section{Rare injuries}

Although most of the injuries from PWC accidents are related to blunt trauma from collisions, the literature also reports rare PWC associated perineal and abdominal injuries. Hydrostatic rectal injuries secondary to the jet stream created by the powerful PWC motor have been reported in the literature. Gill et al. [9] report a case study of a 14 year-old female passenger who fell off the back of an accelerating PWC and suffered forceful propulsion of water from the PWC leading to perforation of the rectosigmoid colon. Specifically, the force of the jet stream overcame the anal sphincter and lake water was injected into the colon causing a perforation at the rectosigmoid junction. Emergent laparotomy revealed significant intraperitoneal contamination, which required a diverting colostomy and delayed anastomosis. Fortunately, the patient recovered and has regained bowel function. Kapur and 
Frei [10] reported 2 similar cases in young females who sustained hydrostatic rectal injuries secondary to being thrown off the back of the PWC. Surgeons were able to successfully repair the rectum and anal sphincter. Szmytkowski et al. [11] reported a case of a 34 year old male passenger who was ejected off the back of a PWC and had lacerations to the anoderm in a radial pattern around the anus. A CT scan confirmed the presence of free air in the retroperitoneal space and a ruptured rectum. The patient required emergent laparotomy and a diverting sigmoid colostomy. After two years the patient has full function of his rectum. Al-Habbal and Brouwer [12] present a similar case study of a 20 year old man who fell backwards off a PWC. He presented with immediate pain and pressure in the perineal area, scrotum and lower abdomen. A contrast CT scan revealed a rare isolated extraperitoneal rectal perforation. The patient required a diverting colostomy and delayed anastomoses at 6 months post-injury. These rare hydrostatic rectal injuries are unique in that no collision had occurred; rather these individuals had fallen off the PWC in a compromised position.

In similar circumstances, vaginal trauma can occur as an individual is struck by the jet stream. Specifically, Haan et al. [5] report an instance of vaginal lacerations from a combination of handlebar straddling and hydrostatic jet injury. Her injuries were severe enough to require operative treatment. In addition to rectal injuries, vaginal injuries and other trauma from the hydrostatic jet can be prevented by wearing proper attire, as is discussed in this review.

Carmel et al. [13] investigated spinal fractures related to PWC use in Israel. They identified eight patients, of which 7 were male with a mean age of 36 . None of these patients were involved in a collision, however five patients suffered L1 burst fractures, one suffered a T12 burst fracture, one other suffered a T12 compression fracture and the last person suffered a L1-L2 compression fracture. All patients were treated conservatively with a thoracolumbar brace and were discharged following a few days in hospital. The authors speculate that these spinal burst fractures were likely related to wave jumping; however the mechanism and type of injury is not well recognized in the literature.

\section{Safety}

PWC safety is a topic of debate and concern among doctors, the coast guard and the industry. Safety recommendations have been proposed as early as 1989 in the scientific literature. Vernberg et al. [2] recommended that: (1) PWCs should be used in an area separate from swimmers; (2) should require riders to be a minimum age; (3) a life jacket should be mandatory; (4) and protective headgear should be required. Unfortunately, these simple safety recommendations still go unheeded by many PWC users two-decades later. More recently, the topic of PWC safety has come to the forefront of the literature and the recommendations remain relatively consistent. Haan et al. [5] suggest that inexperience, inadequate supervision and reckless behavior contribute to PWC related accidents. Similarly, Tsai et al. [3] argued that a lack of both operator experience and ability, contribute to accidents and injuries. Haan et al. [5] advise that stricter regulations and improved training could decrease the incidence of these injuries. Similarly, Kim et al. [4] recommend improved training for inexperienced users, stricture age requirements and improved equipment; including a better braking system and padding on the handlebars. Al-Habbal and Brouwer [12] concur that protective garments, an automatic shut-off switch for the passenger and the requirement of a safe boating certificate would improve PWC safety. Therefore, the key themes seem to be: (1) improved and regulated safety equipment; (2) improved education and training for new riders; (3) and improved safety features on the PWC.
A recent survey by Pikora et al. [8] revealed the current safety practices of PWC users. They reported that $73.3 \%$ of individuals wore 6-8 personal protective equipment items when they used their PWC. As well, $90.9 \%$ of individuals performed 6 or more protective behaviors before using their PWC. This included checking for hazards, checking their PWC, wearing sunscreen, checking weather conditions, etc. Interestingly only $39 \%$ of people checked the water and tide conditions consistently, which is often overlooked, considering poor water conditions can contribute to accidents and injury. As well, very few responders went through their safety check with a water sport buddy. Nevertheless, the authors reported that individuals who used more personal protective equipment were less likely to be injured in the past 12 months [8]. However, this finding could either reflect the preventative effect of protective equipment or that those individuals wearing more equipment are also more cautious PWC riders. In a study by McKnight et al. [14] 612 PWC accident reports were assessed to determine the most common types of errors that lead to injury. The most common error was travelling too close to other vessels, for example when riders travel in groups or are too close to boats. As well, inattention to the water and objects ahead is another common error, which results in collisions with objects like debris, the dock, or other vehicles. The authors also suggest that the lack of experience and training for PWC operators is directly related to the high per-boat accident rate. Interestingly, McKnight et al. [14] found that alcohol consumption was not identified as a major contributor to PWC related accidents. Jones et al. [7] found alcohol contributed to only $6 \%$ of PWC accidents that they reviewed. Kim et al. [4] also found that only a small number of their accidents were attributed to alcohol. Additionally, the United States boating statistics from 2010 attribute only $5 \%$ of PWC accidents to alcohol [1]. Therefore, the role of alcohol consumption in PWC accidents is unclear. There is likely a problem with underreporting as the emergency department is the usual location of data collection for these studies. However, it may be that other factors like inexperience and behavior, as previously discussed, actually do contribute more to collisions and injuries. Related to the idea of experience and behavior is the importance of speed. PWC are high performance vehicles that can exceed $60 \mathrm{mph}$ [6]. Therefore, it is not a surprise that Kim et al. [4] reported that $43 \%$ of the PWC accidents they reviewed were attributed in some part to excess speed. As well, the 2010 boating statistics from the United States state that excessive speed was the fourth most common cause of PWC accidents at $14 \%$ [1]. Therefore, speed is another important factor in PWC accidents and injuries. A commonly overlooked safety recommendation is wearing wetsuit bottoms while riding on a PWC. Wetsuit bottoms are suggested to prevent serious but, rare hydrostatic rectal and vaginal injuries secondary to the powerful jet streams of PWCs. A court ruling in 2006 stated that a specific PWC manufacturer was liable \$3.7 million for the lower abdominal injuries suffered by a female passenger as she fell off a PWC [15]. Similar to the rare injuries discussed above, this PWC operator suffered severe rectal injuries, which were not amenable to surgical repair. From this particular case, experts debated the potential benefit of a seatback to prevent the PWC passengers from falling off the craft. However, others argued that back injuries related to seatbacks might occur. Interestingly, the plaintiffs brought up the idea of a seatstrap that would go across the vehicle and would allow the passenger to more securely hold onto the craft and prevent falling off backwards. The potential drawback of the seatstrap is that it is an active device, unlike a seatbelt for instance, which is a passive device. An active device requires you to actively use it to prevent injury, or in this case actively hold onto the strap. Nonetheless, the experts in the case stressed that PWC users and passengers should wear wet suit 
Citation: Gill RS, Whitlock KA, Jawanda AS, Gill SS, Karmali S (2012) Epidemiology of Personal Watercraft Injuries. J Trauma Treatment 1:112. doi:10.4172/2167-1222.1000112

Page 4 of 4

bottoms that are designed to resist the water pressure of the jet stream should they fall off the back of the craft. This court case highlighted the need for improved PWC design to reduce injuries and increased industry focus on safety.

\section{Conclusion}

Personal watercrafts are high performance aquatic vehicles that continue to grow in popularity. In this extreme water sport, recent evidence suggests that it is a common source of aquatic injuries. The major causes of the injury related to PWC are the result of blunt trauma collisions. However, there is increasing recognition of rare injuries to the perineum and lower abdomen. As a result of increasing recognition of PWC injuries, recommendations have been made to improve safety, operator training and regulations for this extreme water sport. We believe that protective safety equipment including helmets and wetsuit bottoms combined with improved operator education may reduce PWC related injuries. Optimistically, industry and regulators will heed the recommendations, which may curb the high accident rates for PWC operators and passengers.

\section{References}

1. (2010) Recreational boating statistics. United States Coast Guard 16754: 24.

2. Vernberg D, Fine EG, Jagger J (1989) Personal watercraft injuries. JAMA 261: 1883.

3. Tsai A, Rhea JT, Novelline RA (2003) The jet ski open-book pelvic fracture: Diagnosis with multidetector CT. Emerg Radiol 10: 96-98.
4. Kim CW, Smith JM, Lee A, Hoyt DB, Kennedy F, et al. (2003) Personal watercraft injuries: 62 patients admitted to the san diego county trauma services. J Orthop Trauma 17: 571-573.

5. Haan JM, Kramer ME, Scalea TM (2002) Pattern of injury from personal watercraft. Am Surg 68: 624-627.

6. Rubin LE, Stein PB, DiScala C, Grotkau BE (2003) Pediatric trauma caused by personal watercraft: A ten-year retrospective. J Pediatr Surg 38: 1525-1529.

7. Jones CS (2000) Epidemiology of personal watercraft-related injury on Arkansas waterways, 1994-1997: identifying priorities for prevention. Accid Anal Prev 32: 373-376.

8. Pikora TJ, Braham R, Hill C, Mills C (2011) Wet and wild: Results from a pilot study assessing injuries among recreational water users in Western Australia. Int J Inj Contr Saf Promot 18: 119-126.

9. Gill RS, Mangat H, Al-Adra DP, Evan M (2011) Hydrostatic rectosigmoid perforation: A rare personal watercraft injury. J Pediatr Surg 46: 402-404.

10. Kapur SS, Frei LW (2007) Colorectal and vaginal injuries in personal watercraft passengers. J Trauma 63: 1161-1164

11. Szmytkowski J, Dabrowiecki S, Makuch-Burzynska M (2007) Unusual recta injury by personal watercraft. J Trauma 62: 551 .

12. Al-Habbal Y, Brouwer R (2012) Extra-peritoneal rectal perforation caused by water jet: A case report and literature review. Ir J Med Sci 181: 127-129.

13. Carmel A, Drescher MJ, Leitner Y, Gepstein R (2004) Thoracolumbar fractures associated with the use of personal watercraft. J Trauma 57: 1308-1310.

14. McKnight AJ, Becker WW, Pettit AJ, McKnight AS (2007) Human error in recreational boating. Accid Anal Prev 39: 398-405.

15. http://67.21.3.118/research/CaseLevel3/83349 